\title{
Educar é punir? Concepções e práticas educativas de pais agressores.
}

\section{Is educate punishing? Parents' childrearing practices and conceptions}

\author{
Thaís Thomé Seni S. e Oliveira* \\ Docente da Universidade Estadual de Londrina - UEL, \\ Londrina, PR, Brasil
}

\author{
Regina Helena Lima Caldana ** \\ Docente da FFCLRP - Universidade de São Paulo - Ribeirão Preto, SP, \\ Brasil
}

\begin{abstract}
RESUMO
A violência física de pais contra filhos é um dos tipos de violência doméstica e constitui um problema de saúde pública. Buscando colaborar para a compreensão do problema e para estratégias de intervenção com famílias, este trabalho tem o objetivo de investigar concepções sobre o educar e as práticas educativas de pais denunciados. Os entrevistados são pais/mães denunciados ao Conselho Tutelar. Utilizou-se o modelo de entrevista "História de vida temática", constituída pelo relato da história de vida do entrevistado, complementada por um conjunto de tópicos previamente definidos. Foram realizadas seis entrevistas, sendo gravadas, transcritas e analisadas qualitativamente. Os resultados apontam inconsistências entre concepções e práticas educativas, dificuldades em utilizar recursos alternativos à punição física para colocar limites; a falta de suporte em rede social como fatores de risco, e a necessidade de implementar programas de intervenção que promovam a integração entre suas concepções e práticas como educadores.
\end{abstract}

Palavras-chave: Violência Física Doméstica, Práticas Educativas, Intervenção com famílias.

\section{ABSTRACT}

Domestic violence is a known public health problem. This research intends to investigate conceptions and childrearing practices of parents that use physical violence against their children. Interviews with three mothers and three fathers from different families were made. Qualitative methodology was used, through semi-structured interview called "Thematic Life History", where participants expose their personal history since childhood, followed by a previously defined list of topics. Interviews were recorded, transcribed and qualitatively analyzed. Data analysis revealed that parent's conceptions are not corresponding to their 
every day actions with their children; the difficulty of parents at using nonviolent chidrearing practices and a cultural naturalization of physical punishment to establish limits. It also points out parents` Iow social and economical support as a risk factor, as well as the necessity of changes in intervention programs to offer possibilities of joining parents conceptions and practices, aiming the improvement of child`s positive global development.

Keywords: Physical domestic violence, childrearing practices, family intervention programs.

\section{Introdução}

O que é educar? Qual é o papel do pai e da mãe junto ao processo de educação de seus filhos? Qual é a melhor maneira de se educar um filho? Estas são questões que acompanham pais e mães de diferentes culturas e camadas sociais, na atualidade. Cada vez mais, estudiosos do desenvolvimento humano e das relações familiares, assim como a mídia e os meios de comunicação em massa enfatizam a importância da relação entre pais e filhos desde seu início, ou seja, desde a gestação e os primeiros anos de vida desse novo ser que chega ao mundo.

É sabido que cada família se insere num universo sócio-cultural historicamente datado, influenciando as maneiras pelas quais se estrutura e através das quais ocorrem as relações entre seus integrantes, as distintas estratégias de organização dos papéis, dos afetos, do dia-a-dia e de sua sobrevivência econômica.

Uma das expressões desta organização familiar são os recursos utilizados pelos pais ou responsáveis para educar a criança, ou seja, as práticas educativas que utilizam em seu papel de educadores. Tais recursos refletem dimensões culturais, sociais e individuais de concepções, crenças e expectativas em relação à criança e seu desenvolvimento.

Dentro deste contexto, existem famílias que fazem uso de punições físicas em diferentes níveis como "surras", palmadas, beliscões, chegando a níveis graves de agressão contra o corpo da criança, que podem causar queimaduras, fraturas e outras lesões. Atualmente tais práticas são consideradas manifestações de violência e são passíveis de punição para quem as pratica. Porém, buscando compreender o fenômeno, podemos nos perguntar: o que leva um pai ou mãe a praticar uma agressão física contra seu filho? Quais são as concepções, crenças e vivências que estão por trás deste fenômeno? E mais além, como podemos ajudar estas famílias a utilizar outros recursos para educar seus filhos?

Segundo Vicente (2002), a violência física de pais contra a criança resulta de um conflito de gênero ou de gerações, decorrente de uma forma de lidar com as diferenças onde estas são transformadas em 
relação entre superiores e inferiores, sendo o mais fraco tratado como objeto. Deste modo, a criança é vista como o mais fraco da relação paifilho.

Partindo para uma sistematização dos tipos de violência contra a criança o ambiente doméstico, Guerra (2001) e Day et al (2003) consideram quatro tipos de violência: sexual, negligência, psicológica e física, sendo este último o mais tipo freqüente.

Em relação à definição de violência física, é importante ressaltar a diversidade de definições que engendram uma diversidade de posicionamentos: a palmada pode ser considerada uma forma de violência física? Ou só quando deixa marca visível no corpo da criança? Nesta direção, Giovannoni (1993) discute e problematiza esta pluralidade de enfoques, que parte de um continuum que vai de tapas e beliscões até graves espancamentos de crianças. Guerra (2001), em seu estudo sobre as diferentes concepções e definições, diferencia dois critérios para se considerar a existência de violência física doméstica: se há existência de dano, ou seja, ferimentos ou sintomas da agressão no corpo da criança; ou de dor física, ainda que não deixem marca visível. Segundo Day et al (2003) a tendência mundial é considerar violência toda modalidade ou ato disciplinar que atinja o corpo da criança ou adolescente.

No que se refere à lei brasileira, o Estatuto da Criança e Adolescente (1990, Art.98) não especifica tipos ou graus de violência. Apenas prevê medidas de proteção à criança e ao adolescente nos casos: I- por ação ou omissão da sociedade ou do Estado; II- por falta, omissão ou abuso dos pais ou responsável; III- em razão de sua conduta.

\section{Família e práticas educativas: breve histórico}

O primeiro passo para se compreender o fenômeno da violência física de pais contra seus filhos é situar historicamente as concepções sobre a educação de crianças pela família, as práticas educativas utilizadas e o uso da punição física ao longo do tempo.

Assim, no contexto do Brasil, em relação às elites do século XVIII e parte do XIX, temos o modelo familiar patriarcal e a presença da escravidão como aspectos definidores da forma e cuidado de educação dos filhos, constituindo um universo familiar centrado no adulto, com rígida demarcação de papéis, valorização da formação moral, da obediência, da autoridade e do pouco espaço para a afetividade.

Até a metade do século XX os castigos físicos e punições corporais eram práticas educativas socialmente aceitas e recomendadas, sendo utilizadas como instrumento de disciplina moral, garantia de respeito e obediência à autoridade parental, especialmente à figura do pai, que, 
neste contexto, era a figura de autoridade tanto para a esposa quanto para os filhos.

Segundo Figueira (1987), até por volta da década de 50 teria prevalecido em nossa sociedade o ideal de família tradicional, descendente direto da família patriarcal; nela a identidade dos membros é posicional, ou seja, determinada pelas suas características intrínsecas (homem e mulher, pai e filho), determinando uma rígida delimitação de papéis. As regras de conduta são definidas externamente, por valores dicotômicos e maniqueístas, com conceitos de certo e errado muito bem delimitados. Sucedendo a esse ideal, ainda que de forma absolutamente não linear, teríamos o da família igualitária, onde a identidade dos sujeitos é idiossincrática: homens e mulheres, pais e filhos são iguais enquanto indivíduos; as diferenças são atribuídas à individualidade de cada sujeito, e os valores do que é certo ou errado são relativizados.

À medida que a família se transforma (FIGUEIRA, 1987) vão ocorrendo mudanças nos valores e nas práticas da educação da criança na família (BIASOLI-ALVES, 1995; OLIVEIRA; CALDANA 2004), trazendo um enfoque antiautoritário, a preocupação com o desenvolvimento da criança, com seu bem-estar emocional, e a valorização da expressão de afeto e proximidade através do brincar. Dois outros aspectos acompanham este ideário moderno de educação: a forte influência de idéias ligadas à Psicologia e Psicanálise, que situa a infância como período determinante para o desenvolvimento emocional do indivíduo e coloca os pais ou educadores como responsáveis pela saúde emocional do filho (RUSSO, 1987); e a presença de conflitos parentais diante da inexistência de um padrão claro de conduta comumente aceito, e da dificuldade em colocar limites e exercer a autoridade.

\section{Práticas Educativas e Estilos Parentais}

Diante do cenário de transformações culturais ao longo do tempo, é importante ressaltar que as estratégias ou práticas educativas são os recursos utilizados pelo pai ou mãe para orientar o comportamento do filho, buscando atingir objetivos específicos em situações determinadas, tendo como pano de fundo valores e metas que não estão necessariamente conscientes para eles. Segundo Hoffman (1975, 1994 apud BEM; WAGNER, 2006), existem duas categorias de práticas ou estratégias educativas: as indutivas e as coercitivas.

As práticas educativas indutivas são aquelas que indicam à criança as conseqüências de seu comportamento sobre o ambiente, sobre outras pessoas, e sobre si mesma, fazendo-a refletir sobre os aspectos lógicos da situação. Seria um meio de controle indireto, que coloca a criança como responsável pelas conseqüências de seus atos e incentiva a 
empatia com as outras pessoas. Favorecem a internalização de padrões morais, por propiciarem à criança a compreensão dos motivos que justificam a necessidade da mudança de comportamento, colocando-a como sujeito ativo em seu processo educativo.

Por outro lado, as práticas coercitivas envolvem técnicas disciplinares que fazem uso da força e poder dos progenitores, incluindo aí as punições físicas, ameaças, privação de privilégios e afetos. Provocam um controle do comportamento da criança baseado apenas em sanções externas, sendo uma forma de controle direto, que não leva a criança a compreender as implicações de suas ações e não desenvolve a motivação intrínseca para agir de outra forma, a não ser para evitar a punição.

Outro conceito interessante é o de estilos parentais (CECCONELLO, DE ANTONI ; KOLLER, 2003; BEM ; WAGNER, 2006), que referem-se a um conjunto de condutas, traduzindo-se numa tendência global de comportamento e de formas dos pais e mães lidarem com as crianças em determinadas situações educativas. Baseados em duas dimensões, o controle e o afeto, os autores apresentam quatro estilos parentais: autoritário, democrático, indulgente e negligente.

O estilo parental autoritário corresponde a um alto nível de controle por parte do educador, através de castigos físicos, ameaças e proibições. Geralmente comporta altos níveis de exigência não considerando as necessidades e opiniões da criança. Tende a enfatizar a obediência através do respeito à autoridade e à ordem e a não valorizar o diálogo ou a autonomia.

O estilo indulgente resultaria da combinação entre baixo controle e alta responsividade. Pais indulgentes tendem a apresentar tolerância e aceitação dos impulsos da criança, não estabelecendo regras ou limites e permitindo que a criança monitore seu próprio comportamento. São bastante afetivos e comunicativos, tendendo a satisfazer qualquer solicitação da criança. Estabelecem poucas demandas de responsabilidade e maturidade.

Pais negligentes apresentariam baixo controle e baixa responsividade, não sendo afetivos ou exigentes. Tendem a manter distancia na relação com os filhos, respondendo apenas às suas necessidades básicas e estando freqüentemente centrados em seus próprios interesses.

Já o estilo democrático se caracterizaria por um equilíbrio entre afeto e controle, havendo reconhecimento e respeito pela individualidade da criança, tendência a valorizar e promover os comportamentos positivos dos filhos mais do que a restringir os não desejados. Deixam normas e limites bem delimitados, aplicando estratégias disciplinares indutivas, e utilizando-se de comunicação clara e baseada no respeito mútuo. Os 
autores ressaltam que várias pesquisas destacam a influência positiva deste estilo sobre o desenvolvimento de crianças e adolescentes, estando associado à competência social, assertividade e autonomia, dentre outros (CECCONELLO; DE ANTONI; KOLLER, 2003; BEM; WAGNER, 2006).

É importante ressaltar que embora consideremos os processos históricos, sociais e culturais que de alguma forma nos permitem compreender o uso de punições corporais como práticas educativas ao longo do tempo, não se pode deixar de considerar que, no contexto atual, como diversos estudos apontam (BEM ; WAGNER, 2006; LONGO, 2005; CECCONELLO, DE ANTONI ; KOLLER, 2003; MINAYO, 2002; GUERRA, 2001) o uso de punições físicas e castigos corporais não é eficaz como estratégia ou prática educativa, e torna-se prejudicial à criança e ao adolescente na medida em que produz conseqüências negativas ao seu desenvolvimento a curto, médio e longo prazo.

Neste sentido, o objetivo deste trabalho é trazer elementos para a compreensão do fenômeno da violência física de pais contra seus filhos, através da investigação junto a pais e mães denunciados, sobre sua visão a respeito do que é educar uma criança, as práticas educativas que utilizam, seu papel de pai/mãe e as conseqüências de seus comportamentos sobre o filho.

\section{Método}

\section{Instrumento: A Entrevista}

Foi utilizado o modelo "História de Vida Temática", que combina a estratégia de História de Vida com a entrevista semi-estruturada. Assim, a entrevista é realizada em dois momentos: no primeiro solicita-se ao entrevistado o relato da sua "história de vida" com mínima interferência do entrevistador; em seguida, busca-se a complementação das informações já obtidas, de acordo com uma série de tópicos previamente definidos pelo pesquisador, a partir dos objetivos da pesquisa.

É importante destacar que, neste trabalho, optamos por centrar o foco nas experiências e concepções dos entrevistados sobre suas práticas educativas, não fazendo referência direta, em momento algum, à violência ou agressão pela qual foram denunciados.

\section{Participantes}

Os participantes são pais e mães denunciados por violência física contra seu(s) filho(s) ao Conselho Tutelar de Barretos, cidade do interior do estado de São Paulo. 
O convite inicial foi feito pelos conselheiros tutelares, e somente após esse consentimento a pesquisadora entrou em contato com os entrevistados.

Para a delimitação do número de participantes, optou-se pela utilização do "ponto de saturação" (BERTAUX, 1980 apud ALBERTI, 1989). Assim, os dados referem-se a seis entrevistas realizadas com 3 pais e 3 mães, denunciados por uso de violência física contra seus filhos. É importante destacar que em todos os casos apenas o entrevistado havia sido denunciado, sendo assim, os entrevistados pertencem a famílias distintas. Segue abaixo o quadro de caracterização dos entrevistados, lembrando que os nomes são fictícios:

\begin{tabular}{|c|c|c|c|c|c|c|}
\hline Nome ${ }^{1}$ & $\begin{array}{l}\text { nasci- } \\
\text { mento }\end{array}$ & Estado civil & $\begin{array}{l}N^{0} \text { de } \\
\text { filhos }\end{array}$ & $\begin{array}{l}\text { Escolaridadel } \\
\text { Profissāo }\end{array}$ & Renda & Denúncia \\
\hline Janete & 1966 & $\begin{array}{l}\text { Amasiada } \\
\left(2^{a} \text { uniå) }\right.\end{array}$ & 5 & $\begin{array}{c}8^{2} \text { sériel } \\
\text { Trabalhadora rural }\end{array}$ & $\begin{array}{l}\mathrm{R} \$ 370,00 \\
\text { (média) }\end{array}$ & $\begin{array}{l}\text { A gressåo contra a } \\
\text { filha ( } 15 \text { anos) }\end{array}$ \\
\hline Paulo & 1964 & $\begin{array}{l}\text { Amasiado } \\
\left(2^{\mathrm{a}} \text { uniåo) }\right.\end{array}$ & 3 & $\begin{array}{l}1^{\circ} \text { ano ensino médiol } \\
\text { Aux, de prod, }\end{array}$ & $\mathrm{R} \$ 600,00$ & $\begin{array}{l}\text { Agressio contra o } \\
\text { filho (16 mos) }\end{array}$ \\
\hline Vânia & 1975 & $\begin{array}{c}\text { Solteira } \\
\text { ( } 2 \text { uniőes } \\
\text { consensuais) }\end{array}$ & 2 & $\begin{array}{c}1^{\circ} \text { ano do ensino médid } \\
\text { Doméstica }\end{array}$ & $\begin{array}{l}\text { Um salário } \\
\text { mínimo } \\
\text { (R\$300,00) }\end{array}$ & $\begin{array}{l}\text { Espancamento da } \\
\text { filha ( } 11 \text { anos) }\end{array}$ \\
\hline Denise & 1974 & $\begin{array}{c}\text { Casada } \\
\left(2^{*} \text { unila }\right)\end{array}$ & 4 & $\begin{array}{c}\text { Sescrie/ Faqueira } \\
\text { aposentada por } \\
\text { depressåo }\end{array}$ & R\$500,00 & $\begin{array}{l}\text { Agressāo física e } \\
\text { ameaça de morte } \\
\text { aos filhos. }\end{array}$ \\
\hline Michel & 1966 & $\begin{array}{c}\text { Viúvo } \\
\text { Amasiado } \\
\text { (5 uniåo) }\end{array}$ & 3 & $\begin{array}{c}6^{\prime \prime} \text { série/ Eletricista. } \\
\text { Afastado por depressåo }\end{array}$ & R $\$ 500,00$ & $\begin{array}{l}\text { Violencia física } \\
\text { contra o filho ( } 7 \\
\text { anos) }\end{array}$ \\
\hline A ugusto & 1977 & $\begin{array}{l}\text { Divórcio em } \\
\text { processo }\end{array}$ & 2 & $\begin{array}{c}8^{12} \text { série/ Servente de } \\
\text { pedreiro }\end{array}$ & $\begin{array}{l}\text { R\$400,00 } \\
\text { (média) }\end{array}$ & $\begin{array}{l}\text { Violencia física } \\
\text { contra a esposa e } \\
\text { os dois filhos }\end{array}$ \\
\hline
\end{tabular}

Contextualizar alguns dados dos entrevistados auxilia na compreensão de alguns fatores psicossociais. Todos apresentam grau de escolaridade até 01 음 ano do Ensino Médio e renda entre 1 e 2 salários mínimos, podendo ser consideradas famílias de baixa renda ou famílias de camadas populares. Todos se encontram na faixa etária entre 30 e 40 anos.

Em relação à situação conjugal, apenas Augusto, está em sua primeira união, mas já em processo de divórcio. Vânia teve duas uniões consensuais, mas no momento sua família poderia ser considerada matrifocal.

\section{Procedimento para a coleta de dados}

O projeto foi submetido e aprovado pelo Comitê de Ética em Pesquisa da Faculdade de Filosofia, Ciências e Letras de Ribeirão Preto - FFCLRP USP. As entrevistas foram realizadas com pais/mães denunciados ao 
Conselho Tutelar em um momento anterior a qualquer tipo de intervenção ou encaminhamento. A participação foi voluntária e documentada por um termo de consentimento esclarecido. Todas as entrevistas foram realizadas de forma individual, gravadas e transcritas na íntegra, tendo duração média de 1 (uma) hora.

\section{Análise}

As entrevistas foram analisadas de acordo com o modelo proposto por Biasoli-Alves; Dias-da-Silva (1992), que prevê a sistematização das informações obtidas de leitura sucessivas do material acompanhadas de anotações de tudo o que se apreende dos dados e do que eles significam, levando em conta tanto suas regularidades quanto diferenças.

As etapas da análise, dentro do modelo proposto, são as seguintes: 1leitura exaustiva e repetida do material para apreensão de idéias centrais e aspectos relevantes sobre o tema, tendo como pano de fundo os dados complementares; 2- identificação de temas, inicialmente, em cada registro e posteriormente no conjunto do material para a formação de categorias centrais; 3- sistematização de categorias centrais como fruto de constante movimento entre os dados, a abordagem conceitual e a literatura, até a composição de um quadro significativo de análise; 4redação final da análise dos dados visando vinculação com a realidade de modo que os indicativos do trabalho de pesquisa possam embasar reflexões sobre a prática profissional na área (PEGORARO; CALDANA, 2008).

\section{Resultados}

A experiência vivida é importante, porém, mais relevante é a forma como o sujeito se apropria destas vivencias e dos significados que os fatos assumem, ou seja, os sentidos que as experiências subjetivas imprimem, e que delineiam seu passado, presente e perspectivas futuras (OLIVEIRA; CALDANA, 2004).

Neste artigo, fazemos um recorte de uma pesquisa mais ampla (OLIVEIRA, 2006), trazendo as concepções dos entrevistados sobre aspectos do educar e suas práticas educativas. Inicialmente, apresentamos a visão dos pais e mães participantes sobre seu papel como educadores, e posteriormente discorremos sobre a as estratégias educativas utilizadas pelos entrevistados, e a articulação entre suas teorias e suas práticas.

\section{Pais e mães diante do espelho: reflexões sobre seu papel}


As definições dos entrevistados sobre o papel de pai/mãe ressaltam em primeiro plano a proximidade com os filhos e aspectos afetivos: "dar amor e carinho, conversar", seguido pela necessidade de por limites e ensinar valores morais.

Vânia: Mãe tem que educar, tem que dar amor, tem que dar carinho, tem que cuidar, tem que dar tudo o que o filho precisa.

Paulo: Olha, o principal seria esse que eu não tive com meu pai, você ter um diálogo. Principalmente o pai com o filho é necessário ter um diálogo, conversar para expor o que é certo e o que é errado, principalmente. Então é o que eu tenho feito por ele hoje.

Porém, trazem dificuldades na realização da tarefa de dar afeto e colocar limites, seja por dificuldades pessoais na relação com o filho, seja por não poder mais lançar mão do recurso de disciplinar através de punições físicas. É importante destacar que os relatos evidenciam um sentimento de confusão dos pais na forma e no exercer seu papel, na dificuldade de comunicação e de escassez de recursos interpessoais para educar o filho. As falas abaixo ilustram tais aspectos:

Janete: (...) me fala, como é que você educa um filho hoje em dia? não tem jeito, a educação da criação de hoje tá muito ruim, (...) não tem jeito, hoje em dia criar um filho na base da conversa não vira.

Paulo: Aí eu chego naquela conclusão: " será que o problema é comigo? será que alguma coisa de errado eu fiz? ou ele não gosta de mim?" por que de tudo o que a gente explica ou pede para fazer, faz o contrário (...)

Nesse sentido, os pais definem seu papel como educadores a partir da proximidade afetiva com os filhos, mas relatam que no dia-a-dia não conseguem tal aproximação, o que traz angústia e o sentimento de inadequação ao papel ou das estratégias utilizadas.

\section{Quando a conversa não funciona: idéias $x$ práticas}

Apesar de mencionarem como elemento principal do papel de educador a afetividade e o diálogo com o filho, as formas de disciplinamento que utilizam apresentam contradições que apontam que a prática e as situações cotidianas exigem outras ações, sendo o diálogo insuficiente ao pai/mãe para se atingir os objetivos da educação, principalmente se a "conversa" não tem o efeito desejado. O uso de palmadas, chineladas e outras formas de punição física está ligado também à forma de 
conseguir respeito por parte da criança e à "perda da paciência" ou "nervoso" do pai ou da mãe.

Augusto: Ah, disciplino do jeito mais correto, né? Evito de bater, mas no caso o maior, ele fazendo arte, né? Eu procuro conversar, eu chego chamo a atenção dele, falo: "senta quieto" até ficar quieto. Aí eu vou, vou relevando, até que chega um certo ponto que tá teimando demais e aí não tem jeito. Aí eu sou obrigado a dar um ... ele é muito teimoso. Tá muito teimoso, não obedece mais.

Denise: Às vezes assim a gente bate, mas não é uma coisa de espancar, porque tem que chegar um ponto, porque a gente fica falando, falando, cansa os pulmão, cansa a saliva, se deixar dorme sem tomar banho, leva tarefa sem fazer, briga um com o outro de chute, então eles tem que ter respeito com o pai e a mãe, porque se a gente perder as rédeas, aí o mundo lá fora ensina coisa pior, daqui uns dia tá apanhando da polícia.

Nas falas acima fica claro que o bater é utilizado como forma de colocar limite em comportamentos indesejáveis e ser respeitado pelo filho. Por outro lado, alguns entrevistados fazem uma reflexão crítica a respeito do uso da punição física como estratégia educativa, referindo-se à percepção de que tal tipo de estratégia não é eficaz e à busca de outras estratégias:

Paulo: Então eu tenho noção também de coisa errada que eu fiz sobre isso aí, então hoje eu procuro punir ele assim com castigo, não deixando ele fazer alguma coisa que ele quer para poder não tá precisando bater.

Diante disso, podemos questionar: estes pais e mães que fazem uso do bater estão indo a favor ou contra suas concepções sobre educação? A punição física parece arraigada como prática educativa, e só aparece quando mencionam que não conhecem outra forma de colocar limites nos filhos. Porém, em suas reflexões no momento da entrevista, alguns participantes relatam perceber na prática que " bater não funciona" ou que muitas vezes bater não está relacionado ao educar, mas ao "nervoso", ou seja, a uma descarga emocional do pai/mãe. Verbalizam, porém, a dificuldade em encontrar estratégias alternativas, principalmente diante da tarefa de colocar limites, voltando ao "método conhecido".

Alguns relatos apontam também para uma reflexão e avaliação a respeito do próprio comportamento, buscando um limite interno ou 
externo para seu comportamento, que pode também ser entendido como um pedido de ajuda:

Vânia: Eu só batia nela, e muito. Quando ela era menor era do mesmo jeito, mas eu batia tanto nela, eu fico assim pensando porque ninguém fez nada, porque ninguém chamou alguém no começo, quem sabe eu tinha parado.

\section{Discussão}

Tecendo os fios dos dados apresentados, buscamos uma rede de significados, sentidos atuais e históricos, reflexões que nos permitam compreender o tema estudado, multiplicando-o em algumas respostas e muitas questões.

Não se pode reduzir o fenômeno da violência familiar a questões sócioeconômicas, de pobreza ou má distribuição de renda. Porém, é preciso considerar aspectos psicossociais envolvidos na produção da violência intrafamiliar, não podendo negar que a escassez de recursos básicos de sobrevivência constitui um fator de risco para as famílias em diversos aspectos (GIANINI, LITVOC; ELUF NETO, 1999; GOMES et al, 2002), incluindo os recursos que dispõem para educar seus filhos. Assim, a escassez de recursos não se restringe à renda e ao acesso a bens materiais, mas também pode ocorrer em relação aos bens culturais. Durham (1984) aponta a diferença na produção e apropriação de bens culturais pelas diferentes camadas sociais, estando estes em sua maioria à disposição das classes dominantes. Neste sentido, a autora coloca que as classes dominantes são privilegiadas no sentido de terem os recursos, o tempo, o lazer e o treinamento para poder se apropriar dos bens culturais mais elaborados.

A evolução das idéias, da visão da criança e seu desenvolvimento, dos objetivos da educação e dos meios para se atingir tais objetivos podem certamente ser denominados bens culturais. Dessa maneira lança-se a pergunta: como se dá o acesso das classes populares a tais bens culturais?

Durham (1984) coloca que:

As classes populares são privadas desses recursos e têm freqüentemente que produzir elas próprias os bens culturais para seu consumo, de um modo muito mais difícil, muito mais empobrecido e muito menos cumulativo. (p.32)

Porém, mesmo que diversa daquela proveniente de segmentos sociais dominantes, existe uma produção cultural destas famílias. Neste sentido, a investigação de suas idéias, e de suas práticas cotidianas para 
educar seus filhos, remete ao ideário tradicional de educação, que predominou em nosso contexto até por volta da década de 50 (FIGUEIRA, 1987), lembrando que tal ideário caracteriza-se por uma rígida delimitação de papéis familiares e exacerbada autoridade parental. As regras de conduta são definidas externamente, por valores dicotômicos e maniqueístas, com conceitos de certo e errado muito bem delimitados. Remetem então a objetivos educacionais de conotação moral e a uma naturalização cultural e histórica do bater como estratégia educativa. Devemos lembrar que tais práticas remontam a uma concepção de educação em que a "criança educada" era aquela disciplinada e obediente, elementos presentes nos discursos dos entrevistados.

Retomando as idéias de Durham (1984) sobre a apropriação de bens culturais pelas camadas menos favorecidas da população, pode-se considerar as transformações das formas de se ver e se lidar com a criança e os objetivos educacionais, como bens culturais, produto também de contribuições da Psicologia e da Psicanálise através da difusão de idéias e estudos sobre o desenvolvimento infantil, a importância do apego, do brincar, das relações entre pais e filhos entre outras informações (SANTOS,1986; CALDANA, 1991). Assim, podemos inferir que a apropriação destes bens culturais no contexto das pessoas entrevistadas ocorre de maneira diferente, talvez num ritmo mais lento. Dessa maneira, o que predominaria em seu cotidiano é o conhecimento enraizado do passado, possivelmente por estar mais acessível do que as novas informações - os novos bens culturais.

É interessante salientar que a alternativa ao uso da punição física apresentada pelos pais é a "conversa", mas que colocam tal método como ineficiente, o que justificaria o apelo ao uso de outra estratégia, no caso, bater. Podemos, no entanto, nos perguntar o que significa e como é realizada esta "conversa" a que os pais se referem. Nesta direção, a "conversa" com o filho poderia corresponder a um recurso educativo indutivo (CECCONELLO, DE ANTONI ; KOLLER, 2003; BEM ; WAGNER, 2006), que indicaria à criança, através da comunicação clara entre ela e o pai ou mãe, as conseqüências de seu comportamento sobre o ambiente e sobre si mesma, colocando-a criança como responsável pelas conseqüências de seus atos e incentivando-a à empatia com as outras pessoas.

No entanto, retomando a questão do que os participantes consideram como "conversa" com o filho, o que aparece em seus relatos são ordens dirigidas à criança como: "pára menino", "senta quieto", "vá tomar banho", entre outras. Neste contexto, nos perguntamos se a conversa a 
que os pais se referem não seria uma prática autoritária travestida de uma linguagem democrática.

Os dados sugerem que, apesar do discurso a respeito de suas concepções sobre o que é educar e de seu papel neste processo educativo, trazerem elementos como a proximidade afetiva, a comunicação e a orientação, traduzidas em expressões como: "dar amor e carinho", "ter diálogo", "orientar sobre o que pode e o que não pode", nas situações práticas o que acaba prevalecendo são estratégias coercitivas, que configuram estilos parentais autoritários.

Assim, apresentam inconsistências entre as concepções trazidas e as vivências cotidianas como pais-educadores, estando as primeiras relacionadas a um ideário mais moderno e individualista ou igualitário (FIGUEIRA, 1987), onde se considera a individualidade da criança e as necessidades específicas da infância; e por outro lado, as situações cotidianas com os filhos, que parecem remeter os pais ao uso de práticas mais conhecidas para estes, que estariam mais relacionadas ao ideário tradicional de autoridade, respeito e obediência.

Retomando nosso material de análise, podemos observar que o discurso dos entrevistados, no que se refere a idéias sobre educação e formas de se educar um filho, é marcado pela presença de concepções calcadas no modelo igualitário de relações familiares; porém as descrições sugerem que suas atitudes não acompanham este ideário, afinando-se mais de perto a concepções tradicionais de educação de filhos.

Dessa maneira, se as concepções "atualizadas" de educação da criança na família ainda não se traduzem em práticas, e os pais no papel de educadores na "vida real" recorrem a estratégias "tradicionais" como o bater, é importante mais uma vez refletirmos sobre a naturalização cultural e histórica de punições físicas como estratégias educativas utilizadas com a criança.

Podemos dizer que o processo de transformação de valores, condutas e ideários é lento e não linear (FIGUEIRA, 1987). Neste sentido, ações com as famílias por parte de políticas e estratégias de intervenção podem auxiliá-las neste processo, ajudando-as a integrar discurso e prática na tarefa de educar os filhos, por meio do acesso aos elementos que permitem uma compreensão mais completa do que seria um modelo indutivo de educação, em termos da utilização de recursos alternativos às punições físicas, bem como da compreensão de como ocorre o processo de educação, ao longo do tempo, no interjogo entre atitudes de quem educa e respostas da criança. 


\section{Considerações finais}

Em relação ao contexto atual das famílias, é importante observar que quando se trata de definir fatores de risco para a violência física doméstica, o isolamento social das famílias ou a falta de uma rede de apoio social aparece em primeiro lugar (ETHIER; COUTURE; LACHARITÉ, 2004; CECCONELLO; DE ANTONI ; KOLLER, 2003; SANTOS,2002). Esta consideração nos permite pensar que se pretendemos intervir de forma eficaz junto ao problema da violência doméstica, que constitui uma questão de saúde pública em nosso país, devemos priorizar estratégias de intervenção pautadas na prevenção e estruturação de redes de apoio social às famílias, através de serviços especializados da rede pública, nos aparelhos de diferentes áreas como saúde, educação e desenvolvimento social.

Nossa posição, no entanto, é de que para que tais intervenções sejam efetivas, é necessário que aconteçam levando em consideração todo o universo cultural dos pais, partindo de seu acervo de concepções e práticas (GOMES SZYMANSKI, 1994), oferecendo espaços de reflexão e troca, como também apresentando novas formas de significar tais elementos e ampliando as possibilidades de comunicação com os filhos.

Esta estratégia talvez constitua uma maneira de deixar o solo fértil para novas idéias, informações a respeito do desenvolvimento da criança, do papel dos educadores neste desenvolvimento, de objetivos a serem alcançados e ferramentas a serem utilizadas no cotidiano onde se desenrola o processo educativo, no espaço onde a família se encontra e no encontro das relações. Assim, faz-se necessário oferecer novas possibilidades de encontro a estas famílias, novas formas de contato, de qualidade afetiva e assertiva nas relações entre suas crianças e seus adultos.

\section{Referências Bibliográficas}

ALBERTI, V. História Oral: a experiência do Cpdoc. Rio de Janeiro: Centro de Pesquisa e Documentação de História Contemporânea do Brasil, 1989.

BEM, L. A. ; WAGNER, W. Reflexões sobre a construção da parentalidade e 0 uso de estratégias educativas em famílias de baixo nível socioeconômico. Psicologia em Estudo, Maringá. V.11, n.1, p. 63-71, 2006.

BIASOLI-ALVES, Z. M. M.; DIAS-DA-SILVA, M. G. F. Análise qualitativa de dados de entrevista. Paidéia- Cadernos de Educação da FFCL-RP USP, v.2, p. 61-9, 1992. 
BIASOLI-ALVES, Z. M. M. Família e socialização: processos, modelos e momentos. Tese de Livre Docência não-publicada, 132 p., Universidade de São Paulo, Ribeirão Preto, 1995.

CALDANA, R.H.L. Família: mulher e filhos. Três momentos numa revista católica brasileira (1935 a 1988). São Carlos, Dissertação (Mestrado) 229 p., CECH/UFSCar, 1991.

CECCONELLO, A.M.; DE ANTONI, C. ; KOLLER, S. H. Práticas educativas, estilos parentais e abuso físico no contexto familiar. Psicologia em Estudo, Maringá. V.8, p. 45-54, 2003.

DAY, V.P. et al. Violência doméstica e suas diferentes manifestações. Revista de Psiquiatria do Rio Grande do Sul, Porto Alegre. V.1, p. 921, abril de 2003.

DURHAM, E.R. Texto II. In: ARANTES, A.A. (org). Produzindo o passado. São Paulo: Brasiliense, p. 23 - 58, 1984.

ESTATUTO DA CRIANÇA E DO ADOLESCENTE (ECA) - Lei Federal no 8069 de 1990.

ETHIER, L.S., COUTURE, G., LACHARITÉ, C. Risk Factors Associated with the Chronicity of High Potential for Child Abuse and Neglect. J ournal of Family Violence, Vol. 19, no 1, p.13 - 24, February 2004.

FIGUEIRA, S. A. O "moderno" e o "arcaico" na nova família brasileira: notas sobre a dimensão invisível da mudança social. In: RIBEIRO, I. Uma nova família? O moderno e o arcaico na família de classe média brasileira. Rio de Janeiro, p. 11-30, 1987.

GUERRA, V. N. A. Violência de pais contra filhos: a tragédia revisitada. São Paulo: Cortez, 2001.

GIANINI, R.J.; LITVOC, J.; ELUF NETO, J. Agressão Física e Classe Social. Revista Saúde Pública, São Paulo, V. 33 n.2, p.180-186, 1999.

GIOVANNONI, J. Definitional issues in child maltreatment. In: CICCHETTI, D. e CARLSON, V. (org.) Child Maltreatment theory and research on the causes and consequences of child abuse and neglect. University of Cambridge, NY, 1993.

GOMES, R. et al. Por que as crianças são maltratadas? Explicações para a prática de maus-tratos infantis na literatura. Cadernos de Saúde Pública, Rio de Janeiro, V.18, n.3. p. 707-714, mai-jun 2002.

GOMES SZYMANSKI, H. Educação para a família: uma proposta de trabalho preventivo. Revista Brasileira de Crescimento e Desenvolvimento Humano, V.1, p. 34-39, São Paulo 1994.

LONGO, C.S. Ética disciplinar e punições corporais na infância. Revista Psicologia USP, São Paulo, V.16 n.4, p. 99-119, 2005.

MINAYO, M.C.S. O significado social e para a saúde da violência contra crianças e adolescentes. In: WESTPHAL, M.F. (Org.) Violência e 
Criança. São Paulo: Edusp, 2002.

OLIVEIRA, T. T. S. S. Educar é punir? Compreendendo pontos de vista de pais denunciados por violência física contra seus filhos. 2006. 107 p. Dissertação (Mestrado em Psicologia) Faculdade de Filosofia, Ciências e Letras de Ribeirão Preto - Universidade de São Paulo. Ribeirão Preto, 2006.

OLIVEIRA, T.T.S.S.; CALDANA, R. H. L. Mães Psicólogas ou Psicólogas Mães: Vicissitudes na Educação dos Filhos. Estudos de Psicologia de Natal, Natal RN, v. 9 n.3, p. 585- 593, 2004.

PEGORARO, R. F.; CALDANA, R. H. L. Sofrimento psíquico em familiares de usuários de um Centro de Atenção Psicossocial. Interface Comunicação, Saúde, Educação, v.12, n.25, p.295-307, 2008.

RUSSO, J. A. A difusão da psicanálise nos anos 70: indicações para uma análise. In: RIBEIRO, I. (Org.), Família e valores. São Paulo: Loyola, p. 189-204, 1987.

SANTOS, M.C.C.L. Raízes da violência na criança e danos psíquicos. In: WESTPHAL, M.F.(org.) Violência e Criança. São Paulo: Edusp, 2002.

SANTOS, T.C. De Dona Letícia a Carmem da Silva: As revistas femininas e a modificação do comportamento da mulher. In: RIBEIRO, I. Uma nova família? O moderno e o arcaico na família de classe média brasileira. Rio de J aneiro: Zahar, 1986.

VICENTE, C. M. O direito à convivência familiar e comunitária: uma política de manutenção do vínculo. In: KALOUSTIAN, S.M. (org.) Família Brasileira, a base de tudo. São Paulo: Cortez, 2002.

\section{Endereço para correspondência}

Thaís Thomé Seni S. e Oliveira

Depto Psicologia e Psicanálise, Universidade Estadual de Londrina - UEL, Rodovia Celso Garcia Cid, Pr 445 Km 380, Campus Universitário, CEP 86051-990, Londrina- PR, Brasil Endereço eletrônico: thasenne@gmail.com

Regina Helena Lima Caldana

Depto de Psicologia e Educação, Faculdade Filosofia Ciências e Letras Ribeirão Preto, Universidade de São Paulo, Av Bandeirantes 3900, CEP 04071-000, São Paulo - SP, Brasil

Endereço eletrônico: rhlcalda@ffclrp.usp.br

Recebido em: 27/05/2008

Aceito para publicação em: 16/09/2009

Acompanhamento do processo editorial: Eleonôra Torres Prestrelo

\section{Notas}

* Mestre em Psicologia pela FFCLRP - Universidade de São Paulo - Ribeirão Preto.

** Doutora em Educação pela Universidade Federal de São Carlos, UFSCAR. 